Sir,

\section{Bilateral idiopathic retinal telangiectasis, progressive neuroradiological abnormalities and ectodermal dysplasia}

Idiopathic retinal telangiectasis is an uncommon retinal vascular disorder characterised by telangiectatic retinal vessels with varying amounts of intraretinal and subretinal exudation. ${ }^{1}$ Idiopathic retinal telangiectasis is a spectrum of disease predominantly affecting one eye of male patients, in both children and adults. ${ }^{1-4}$ The most severe cases are similar to those described by Coats and result in retinal detachment with subsequent secondary uveitis, cataract and rubeotic glaucoma. ${ }^{2}$ Bilateral idiopathic retinal telangiectasis has been reported in association with a number of syndromes including retinitis pigmentosa and facioscapulohumeral muscular dystrophy. ${ }^{5,6}$ Recently five cases of idiopathic retinal telangiectasis in association with dyskeratosis of varying severity and in some instances intracranial calcification have been reported. ${ }^{7-10}$ We present a case of bilateral idiopathic retinal telangiectasis, progressive neuroradiological abnormalities and ectodermal dysplasia in a young girl and compare our findings with marked similarities in previously reported cases.

\section{Case report}

A 3-year-old girl was referred for ophthalmological review as part of investigations for developmental delay. This patient was born at 37 weeks gestation by caesarean section for intrauterine growth retardation (birth weight $2.2 \mathrm{~kg}$ ) despite no maternal illnesses. A full neonatal ophthalmological examination, performed while the patient received treatment for necrotising enterocolitis, was normal. At the time of referral this patient had two male siblings (one older and one

Table 1. Bilateral idiopathic retinal telangiectasis, progressive neuroradiological abnormalities and ectodermal dysplasia: comparison of data from this report and previously published reports

\begin{tabular}{|c|c|c|c|c|c|c|}
\hline & This report & Tolmie et al..$^{7}$ & $\begin{array}{l}\text { Revesz et al. } \\
\text { (Revesz } \\
\text { syndrome) }\end{array}$ & $\begin{array}{l}\text { Kajtar and } \\
\text { Mehes }^{9} \\
\text { (Revesz } \\
\text { syndrome) }\end{array}$ & $\begin{array}{l}\text { Newell et al. } \\
\text { (Hallermann-Streiff } \\
\text { syndrome) }\end{array}$ & $\begin{array}{l}\text { Davidson and Connor }{ }^{11} \\
\text { (Congenital dyskeratosis) }\end{array}$ \\
\hline No. of cases: & $n=1$ & $n=2$ & $n=1$ & $n=1$ & $n=1$ & $n>104$ \\
\hline Gender: & Female & Female & Male & Female & Male & Male and female \\
\hline Age of onset: & 3 years & $\begin{array}{l}\text { Approximately } \\
3 \text { years }\end{array}$ & 6 months & 2 years & 3 months & Mean age 7 years \\
\hline $\begin{array}{l}\text { Retinal } \\
\text { telanglectasis: } \\
\text { Growth: }\end{array}$ & Bilateral & Bilateral & Bilateral & Bilateral & Bilateral & No \\
\hline IUGR: & Yes & Yes & Yes & Yes & No & No \\
\hline $\begin{array}{l}\text { Short stature: } \\
\text { Head }\end{array}$ & Yes & Yes & No & Yes & Yes & Yes $(13 \%)$ \\
\hline $\begin{array}{l}\text { circumference: } \\
\text { Dyskeratosis: }\end{array}$ & Reduced & Reduced & Normal & Reduced & Reduced & Normal \\
\hline Fine sparse hair & :Yes & Yes & Yes & Yes & Yes & Yes $(34 \%)$ \\
\hline $\begin{array}{l}\text { Nail dystrophy: } \\
\text { Skin }\end{array}$ & Yes & Yes & Yes & Yes & No & Yes $(92 \%)$ \\
\hline $\begin{array}{l}\text { pigmentation: } \\
\text { Tongue }\end{array}$ & No & No & Yes & Yes & No & $\begin{array}{l}\text { Yes }(99 \%) \\
\text { Yes }(82 \%)\end{array}$ \\
\hline $\begin{array}{l}\text { leukoplakia: } \\
\text { Neurological: }\end{array}$ & No & No & Yes & Yes & No & \\
\hline $\begin{array}{l}\text { Cerebral } \\
\text { calcification: }\end{array}$ & Yes & Yes & Yes & No & No & Yes (Rare) \\
\hline $\begin{array}{l}\text { Ataxia: } \\
\text { Mental }\end{array}$ & Yes & Yes $^{a}$ & Yes & No & No & No \\
\hline retardation: & No & No & Yes & No & No & Yes $(10 \%)$ \\
\hline Other features: & $\begin{array}{l}\text { Hypoglycaemia } \\
\text { after general } \\
\text { anaesthesia }\end{array}$ & $\begin{array}{l}\text { Seizures in } \\
\text { one sibling }\end{array}$ & $\begin{array}{l}\text { Aplastic anaemia } \\
\text { Retropharynx } \\
\text { haemangioma }\end{array}$ & $\begin{array}{l}\text { Aplastic } \\
\text { anaemia }\end{array}$ & $\begin{array}{l}\text { Dyscephaly } \\
\text { Dental abnormalities } \\
\text { Bilateral congenital } \\
\text { cataracts } \\
\text { Microphthalmia }\end{array}$ & $\begin{array}{l}\text { Hyperkeratinisation }(69 \%) \\
\text { Aplastic anaemia }(51 \%) \\
\text { Dental abnormalities }(12 \%) \\
\text { Hepatosplenomegaly } \\
(7-15 \%) \\
\text { Neoplasia }(12 \%)\end{array}$ \\
\hline $\begin{array}{l}\text { Chromosomal } \\
\text { analysis: }\end{array}$ & Normal & Normal & Normal & Normal & Normal & $\mathrm{Xq} 28$ \\
\hline
\end{tabular}

IUGR, intrauterine growth retardation.

${ }^{a}$ Only one sibling with a history of seizures had ataxia. 


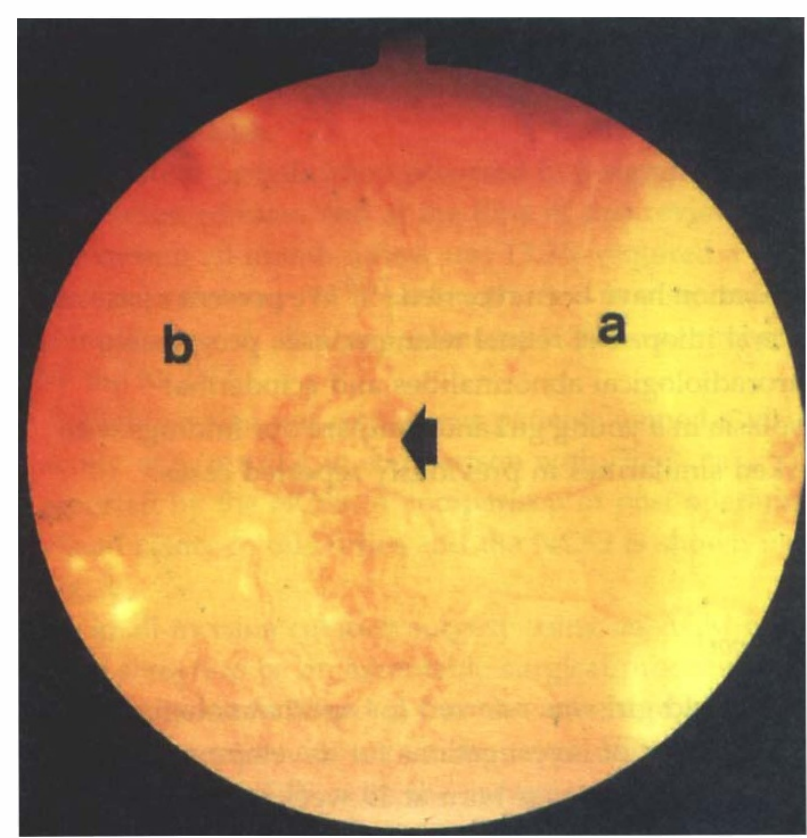

Fig. 1. Photograph of the right temporal fundus demonstrating telangiectatic vessels (arrow) associated with area of retinal exudation (a) and relatively avascular retina (b).

younger) both of whom were healthy. Subsequent ophthalmic examination of both these siblings and both parents was normal.

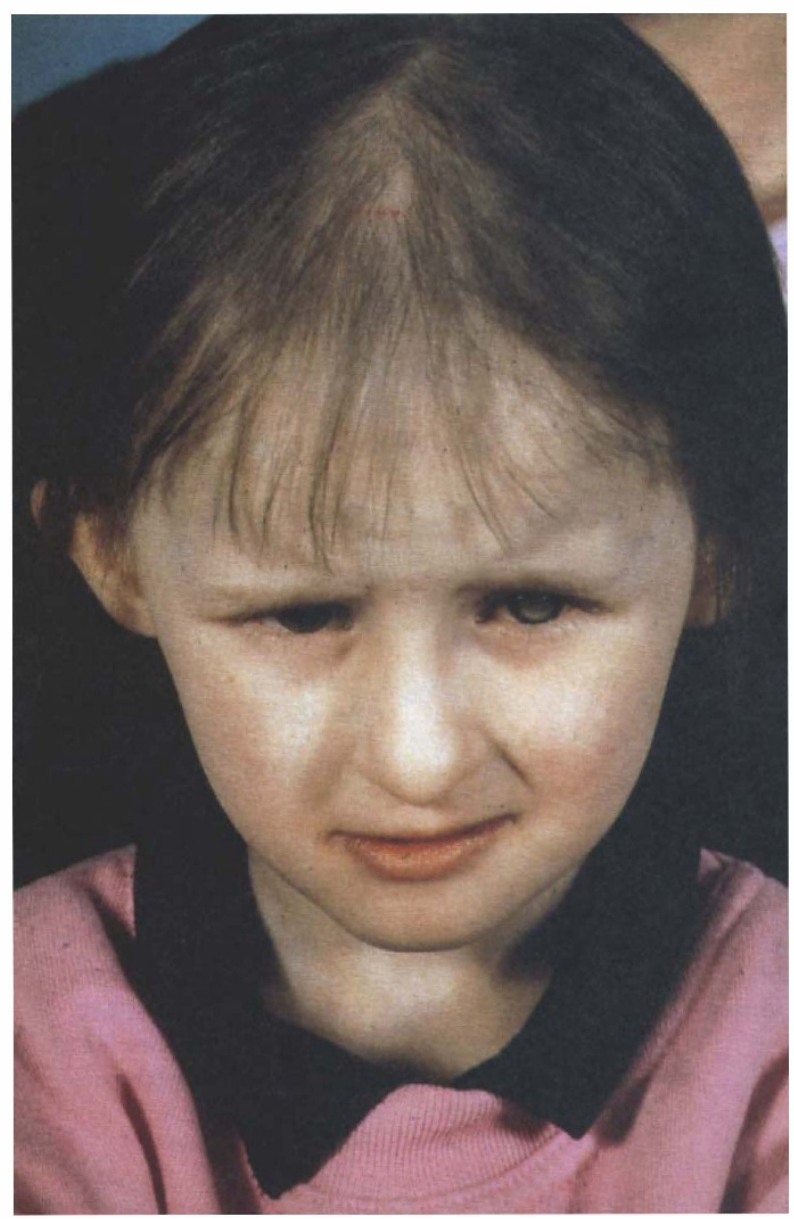

(a)
Initial visual acuity was not assessable, but the patient was orthotropic and intraocular pressures were normal. Fundoscopy demonstrated telangiectatic vessels temporal to the right macula with an associated small area of subretinal exudation and avascular retina in the temporal periphery (Fig. 1). The right macula was normal. In the left eye the telangiectatic vessels were more widespread, particularly temporally, with an exudative detachment involving the macula which was scarred with mottled hyperpigmentation. Argon laser photocoagulation was applied to the telangiectatic vessels in both eyes.

Systemic examination demonstrated short stature and a small head circumference both under the third percentile. Abnormal ectodermal features included fine, sparse hair, short fingers and mild toenail dysplasia (Fig. $2 a-c)$. Assessment of intellect was within normal limits using the Reynell-Zenkin scale. All blood parameters including a full metabolic screen were normal. Brain CT demonstrated thalamic calcification while MRI of the brain demonstrated non-enhancing intracranial white matter lesions located bilaterally in the frontal and parietal lobes, the thalami and the left dentate nucleus consistent with demyelination (Fig. 3a-c).

After further argon laser photocoagulation and trans pars plana vitrectomy with retinal detachment repair, visual acuity in the right eye is $6 / 9$ at 3 year follow-up,

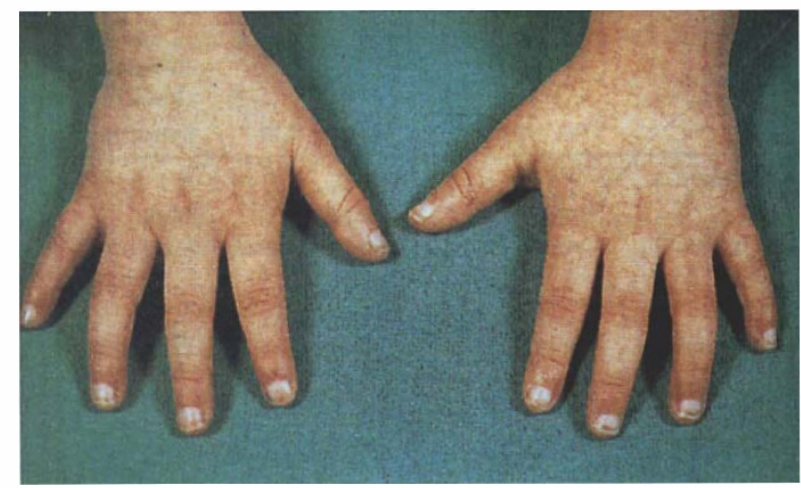

(b)

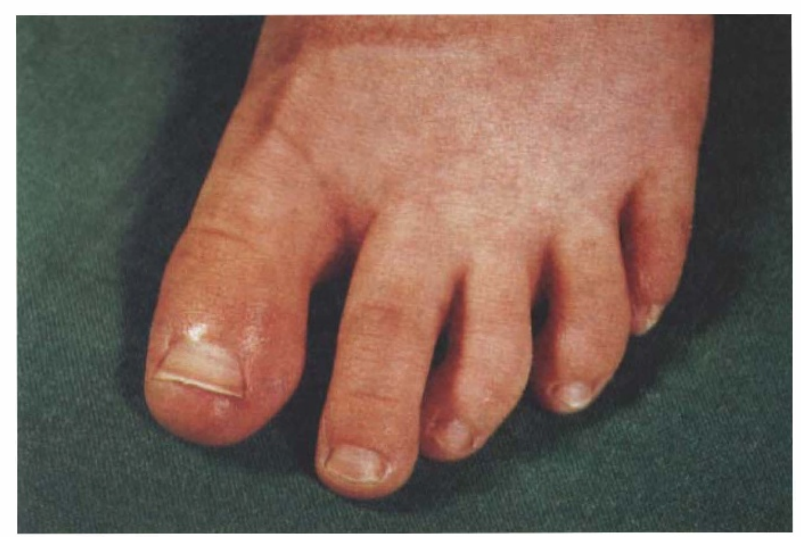

(c)

Fig. 2. Photographs of the patient demonstrating abnormal ectodermal features: (a) fine, sparse hair, (b) short fingers, (c) slight toenail dysplasia. 


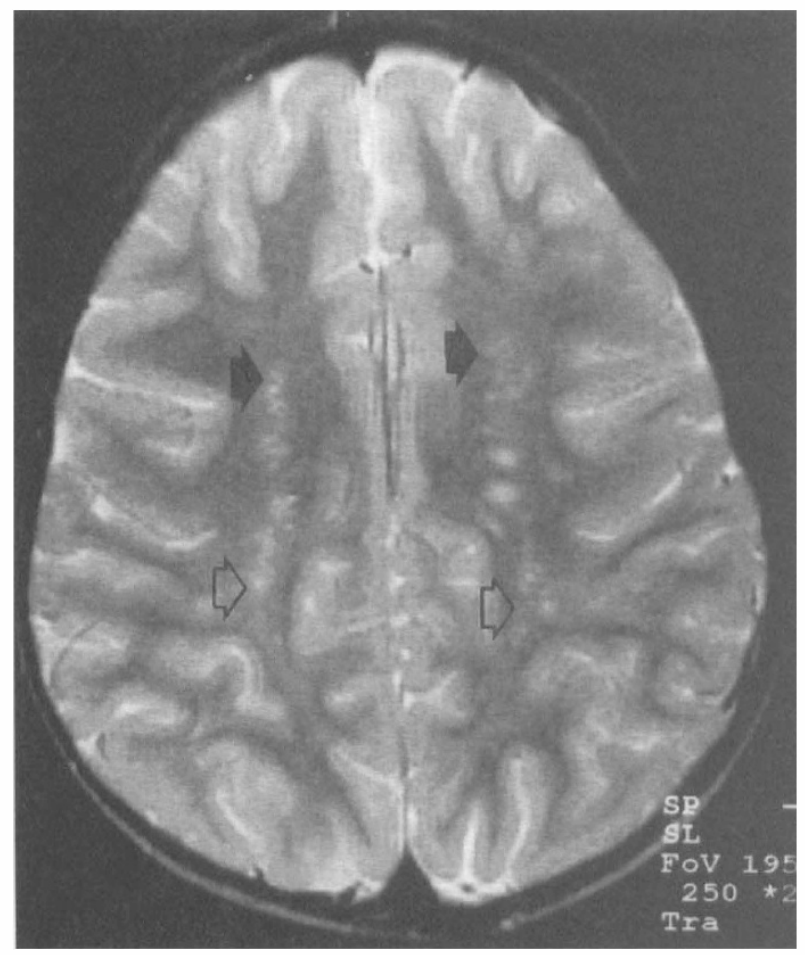

(a)

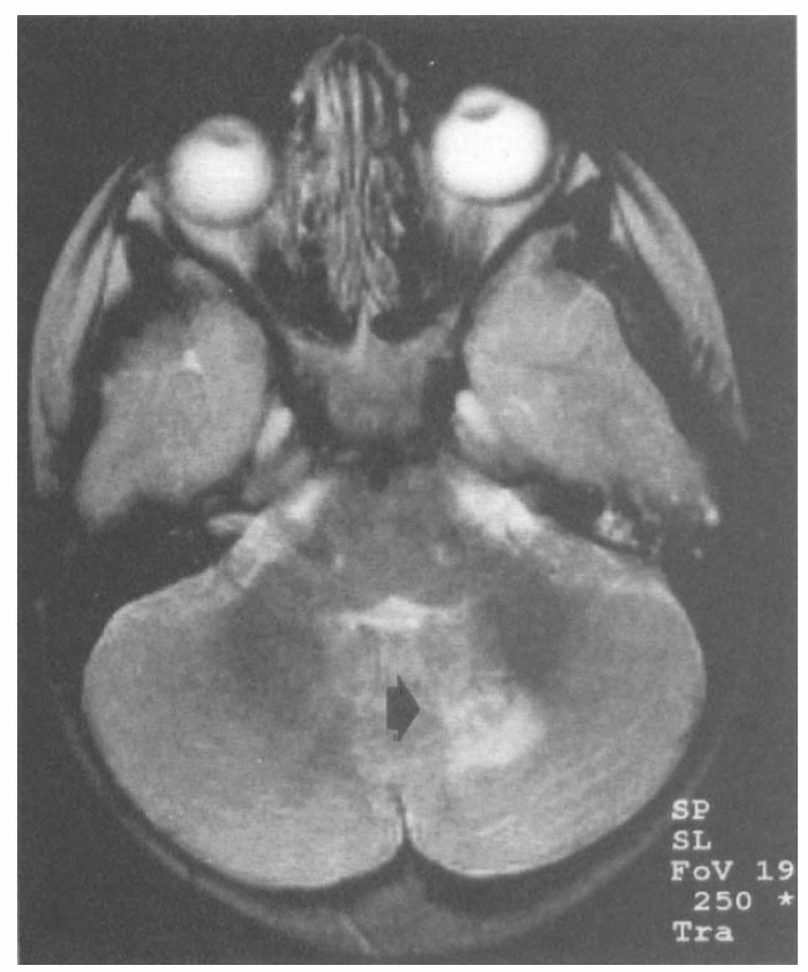

(c)

but NPL in the left secondary to total retinal detachment. Growth measurements remain below the third percentile, there is evidence of a left-sided intention tremor and mild cerebellar ataxia but intellect is normal. Although two episodes of severe hypoglycaemia after general anaesthesia were documented, biochemical, metabolic and chromosomal analysis have been normal. Subsequent MRI scans have demonstrated progression of

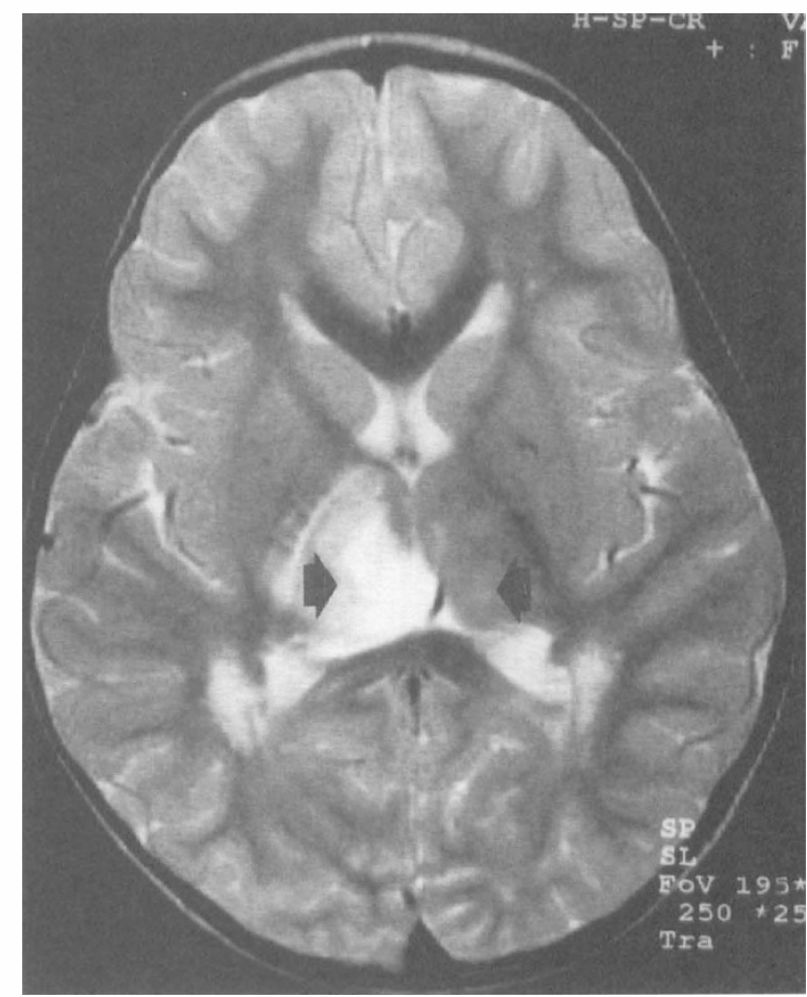

(b)

Fig. 3. Axial T2-weighted MR images taken at presentation. (a) The scan demonstrates high-intensity signals from white matter lesions seen bilaterally in the parietal (open arrows) and frontal lobes (filled arrows). (b) Similar signals are seen bilaterally in the thalami (arrows). (c) This initial scan also shows lesions in the left dentate nucleus (arrow).

the white matter lesions (Fig. 4a-c). Table 1 compares this report with previous similar reports and congenital dyskeratosis.

\section{Discussion}

The association of bilateral idiopathic retinal telangiectasis with ectodermal dysplasia and in some instances intracranial calcification has been previously 


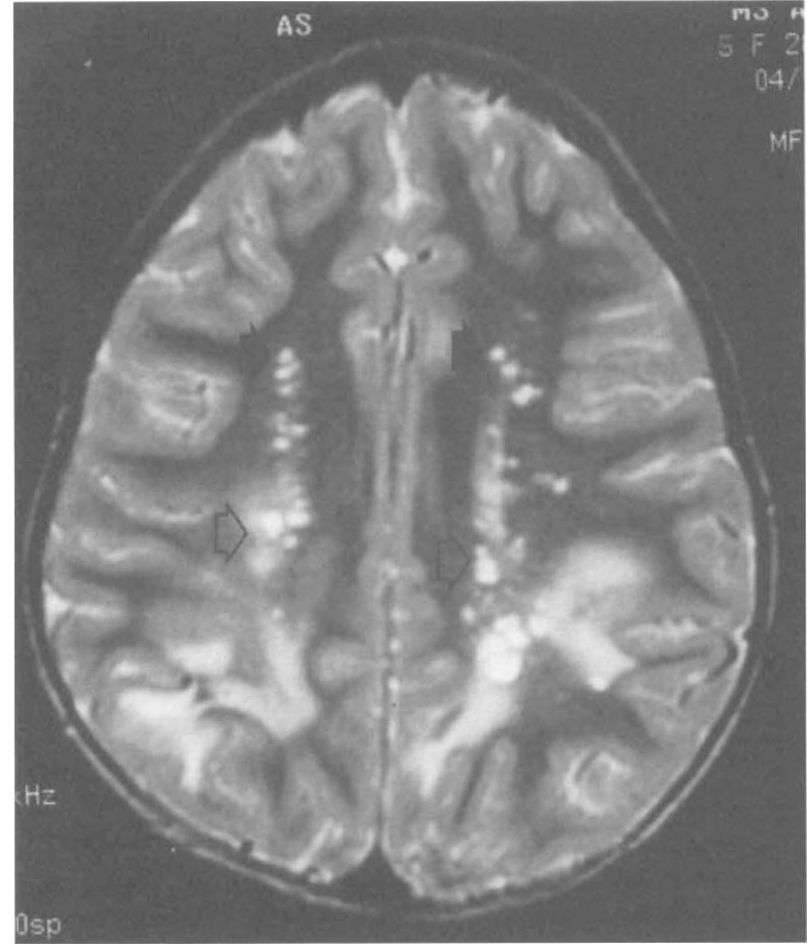

(a)

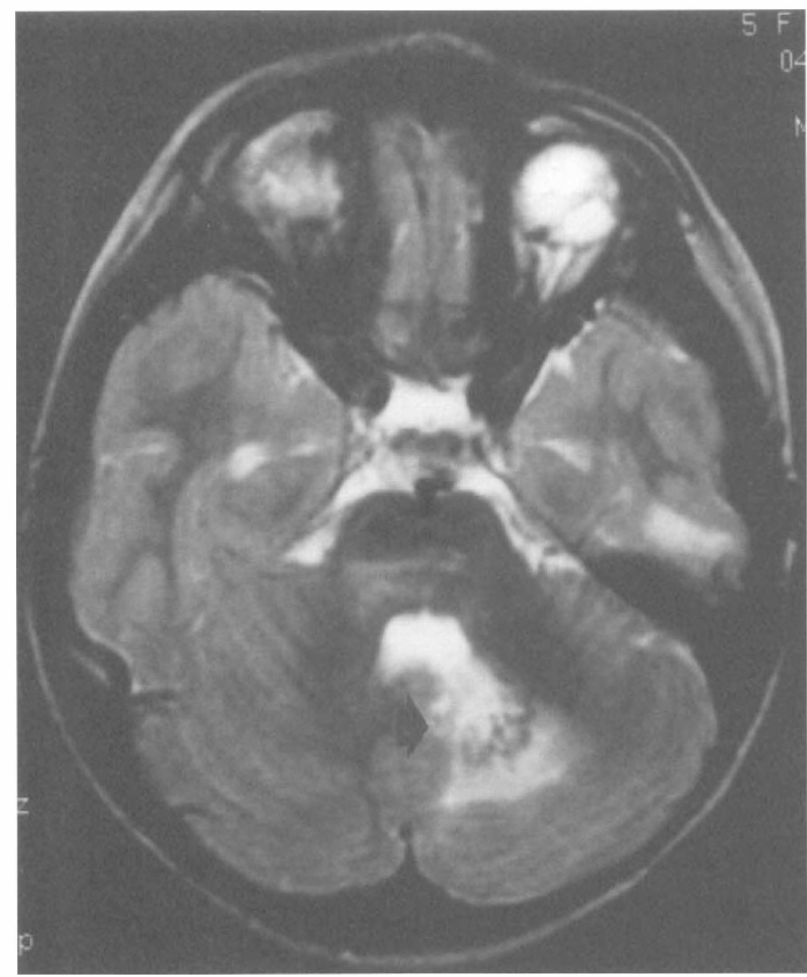

(c)

reported in five cases. ${ }^{7-10}$ In particular the case reported in this paper is nearly identical to two female siblings both with retinal telangiectasis, intracranial calcification, fine, sparse hair and dystrophic nails. ${ }^{7}$ Other similarities include intrauterine growth retardation, early presentation preceded by a period of clinically normal vision, and persistent short stature and small head circumference; histological examination of an enucleated eye of the older sister confirmed the diagnosis of retinal

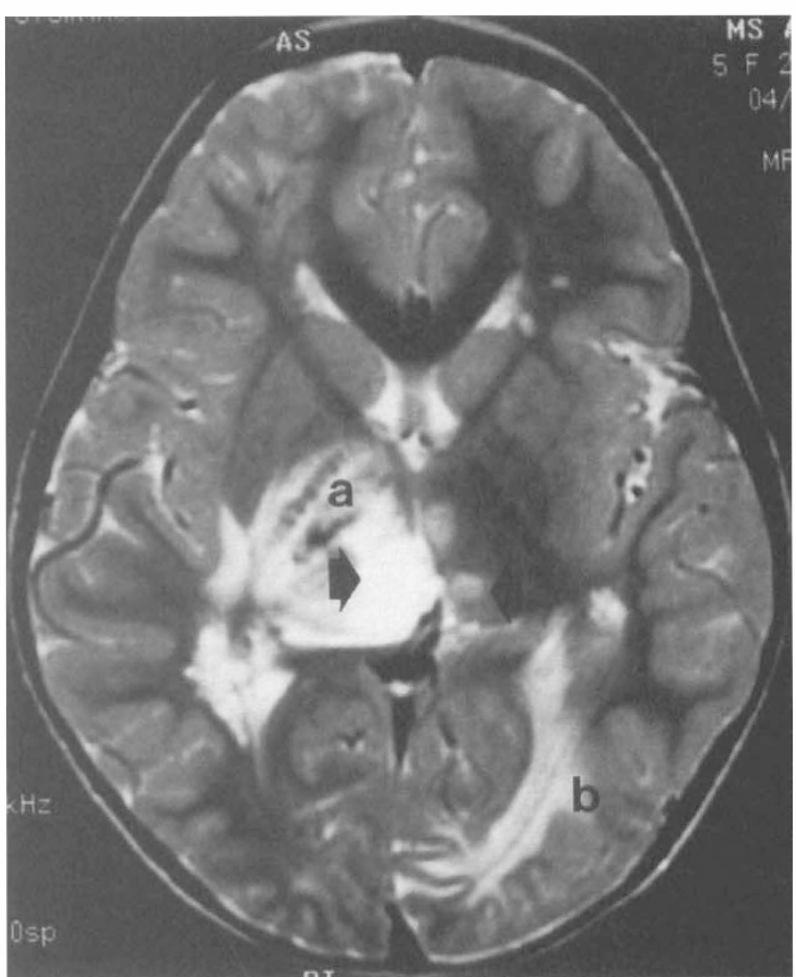

(b)

Fig. 4. Axial T2-weighted MR images taken at 3 year follow-up. (a) There are an increased number of lesions bilaterally in the parietal (open arrows) and frontal lobes (filled arrows). (b) There is

enlargement of the previously seen areas of increased signal intensity in the thalami (arrows) with an associated central area of low signal intensity (a) and a new area of high signal intensity in the left optic radiation (b). (c) The area of high intensity signal has also increased in size in the dentate nucleus (arrow).

telangiectasis and exudation. ${ }^{7}$ As in the case presented here useful vision was preserved in one eye in each child with treatment. No subsequent neuroradiological images of these two cases were reported nor were MRI images available. However, the younger sibling had developed progressive cerebellar ataxia and an intention tremor similar to the patient in this report, which we have attributed to the progressive intracranial white matter abnormalities. While the radiological findings in our 
patient are characteristic of demyelination, there are similarities with the MRI findings reported in association with sub-acute necrotising encephalomyelopathy. ${ }^{11}$

Two further separate reports of Revesz syndrome are very similar to these three cases except that both patients had severe aplastic anaemia and one patient did not have intracranial calcification. ${ }^{8,9}$ These patients also had more typical skin signs of dyskeratosis congenita including skin pigmentation and leukoplakia, although dyskeratosis congenita has not been associated with ophthalmic abnormalities and the age of onset is usually in the second decade. ${ }^{12} \mathrm{~A}$ fifth patient has been reported who demonstrated mild dyskeratosis including sparse hair and abnormal dentition with retinal telangiectasis, but this child had characteristics distinct to oculomandibulofacial dyscephaly (Hallerman-Streiff syndrome).$^{10}$

No chromosomal abnormalities have been found in our case or any of the previously reported cases of retinal telangiectasis and dyskeratosis, but the small number of cases to date in the absence of a family pedigree may preclude assumptions regarding a mode of inheritance. Dyskeratosis congenita has been linked to locus Xq28 and pedigree analysis has suggested an X-linked inheritance in non-sporadic cases. ${ }^{12}$

As in all cases of bilateral idiopathic retinal telangiectasis repeated examinations and aggressive treatment with laser photocoagulation increase the likelihood of preserving useful vision in at least one eye. ${ }^{5-7,10,13}$ While the girl presented in this report has remained normal intellectually the documented progressive intracranial white matter lesions may result in deterioration of neurological function in the long term.

In conclusion, we present a third case of a familial syndrome characterised by idiopathic retinal telangiectasis, progressive intracranial calcification and ectodermal dysplasia. While not identical, similarities between these three cases, Revesz syndrome and Hallermann-Streiff syndrome suggest that these may all be variable expressions of an as yet unidentified underlying genetic abnormality.

\section{References}

1. Reese AB. Telangiectasis of the retina and Coats' disease. Am J Ophthalmol 1956;42:1-8.

2. Coats G. Ueber retinitis exudativa (retinitis haemorrhagica externa). Graefes Arch Ophthalmol 1912;81:275-327.

3. Casswell AG, Clifford-Jones R, Grewal K, Gregor ZJ. Isolated retinal telangiectatic masses. Trans Ophthalmol Soc UK 1986;105:94-9.

4. Gass JD, Blodi BA. Idiopathic juxtafoveolar retinal telangiectasis: update of classification and follow-up study. Ophthalmology 1993;100:1536-46.

5. Khan JA, Ide $\mathrm{CH}$, Strickland MP. Coats'-type retinitis pigmentosa. Surv Ophthalmol 1988;32:317-32.

6. Pauleikhoff D, Bornfeld N, Bird AC, Wessing A. Severe visual loss associated with retinal telangiectasis and facioscapulohumeral muscular dystrophy. Graefes Arch Clin Exp Ophthalmol 1992;230:362-5.
7. Tolmie JL, Browne BH, McGettrick PM, Stephenson BP. A familial syndrome with Coats' reaction retinal angiomas, hair and nail defects and intracranial calcification. Eye 1988;2:297-303.

8. Revesz T, Fletcher S, Al-Gazali LI, DeBuse P. Bilateral retinopathy, aplastic anaemia and central nervous system abnormalities: a new syndrome? J Med Genet 1992;29:673-5.

9. Kajtar P, Mehes K. Bilateral Coats' retinopathy with aplastic anaemia and mild dyskeratotic signs. Am J Genet 1994;49:374-7.

10. Newell SW, Hall BD, Anderson CW, Lim ES. Hallerman-Streiff syndrome with Coats disease. J Pediatr Ophthalmol Strabismus 1994;31:123-5.

11. Heckmann J, Eastmann R, Handler L, et al. Leigh disease (sub-acute necrotizing encephalomyelopathy): MR documentation of an acute attack. Am J Neuroradiol 1993;14:1157-9.

12. Davidson IR, Connor JM. Dyskeratosis congenita. J Med Genet 1988;25:843-6.

13. Pauleikhoff D, Wessing A. Long-term results of the treatment of Coats disease. Fortschr Ophthalmol 1989;86:451-5.

M. Cahill ${ }^{1,2}$

A. Mulvihill ${ }^{1}$

R.W. Acheson ${ }^{2}$

M. O'Keefe

${ }^{1}$ Department of Paediatric Ophthalmology

The Children's Hospital

Dublin 1, Ireland

${ }^{2}$ The Institute of Ophthalmology

Mater Miscericordiae Hospital

Dublin, Ireland

Mr Mark Cahill

Department of Paediatric Ophthalmology

The Children's Hospital

Temple Street

Dublin 1, Ireland

Tel: + 35318748763

Fax: +35318748355

e-mail: mcahill@indigo.ie

\section{Sir}

Indocyanine green angiography in a case of idiopathic retinal vasculitis, aneurysms and neuroretinitis The term idiopathic retinal vasculitis, aneurysms and neuroretinitis (IRVAN) was first applied by Chang and associates ${ }^{1}$ in 1995, although sporadic reports of this condition had previously been described. ${ }^{2-5}$ This rare, bilateral disease - only 15 patients have been reported in the literature - typically affects young healthy individuals.

We report a patient who appeared to present with features typical of IRVAN and who showed abnormalities of the choroidal vasculature as demonstrated by indocyanine green (ICG) angiography. To our knowledge this is the first report of ICG findings in this condition.

\section{Case report}

A 42-year-old Italian woman presented in October 1997 with a 3 week history of reduced central vision in her right eye. She was taking no medications and she had had no preceding systemic illness. The patient was the product of an uneventful full-term pregnancy. Her 